\title{
Study on the Quality of Quasi-Isotropic Composite Laminates Containing a Circular Hole
}

\author{
Venkateswaran Santhanakrishnan Balakrishnan ${ }^{1}$, Holger Seidlitz ${ }^{1}$, Marcello Ambrosio ${ }^{1} \&$ Tilo Schuhmann $^{2}$ \\ 1 Department of Lightweight Design with Structured Materials, Brandenburg University of Technology \\ Cottbus-Senftenberg, Germany \\ 2 Tisora Sondermaschinenbau GmbH, Chemnitz, Germany \\ Correspondence: Venkateswaran Santhanakrishnan Balakrishnan, Department of Lightweight Design with \\ Structured Materials, Brandenburg University of Technology Cottbus-Senftenberg, Germany. Tel: \\ 49-0-355-693-138. E-mail: santhven@b-tu.de
}

Received: August 18, 2017

Accepted: August 28, 2017

Online Published: September 18, 2017

doi:10.5539/jmsr.v6n4p67

URL: https://doi.org/10.5539/jmsr.v6n4p67

\begin{abstract}
Composite structures used in modern engineering applications are often subjected to circular holes in order to join with metal components via riveting, bolting or pinning joints. These design based holes will interrupt the force flux in the direction of the fibers and create high stress concentrations near the notched area. Objective of the project is to understand the quality of the quasi-isotropic composite laminates $\left(\left[45^{\circ},-45^{\circ}, 0^{\circ}, 90^{\circ}\right]_{\mathrm{s}}\right)$ containing circular hole. To achieve this objective, a 3-phase portal milling machine and a $5 \mathrm{~kW}$ continuous wave (cw) $\mathrm{CO}_{2}$ laser system were used to produce the circular holes in the composite laminates. The processing parameters for both the processes are varied to understand its influence. The quality of the circular hole produced by these methods are further investigated and compared in order to arrive at the optimum processing parameters for the given quasi-isotropic composite laminates.

The hole qualities were evaluated by means of delamination factor caused by milling; cone angle, matrix evaporation for $\mathrm{cw}-\mathrm{CO}_{2}$ laser system. For further comparisons, the optimal parameter combinations of both methods were selected for a tensile test according to the standard ASTM D5766-2002.
\end{abstract}

Keywords: circular hole, composite, $\mathrm{CO}_{2}$ laser, drilling, fiber reinforced polymer (FRP), notch

\section{Introduction}

Fiber reinforced polymer (FRP) laminates have high stiffness and strength to weight ratio. Stiffness and strength play important roles in restraining design and to improve vehicle crashworthiness. As a result, FRP laminates were preferred engineering material for structural applications in automotive, aerospace, wind energy and marine industries. About $30 \%$ of the external surface area of the Boeing 767 consists of composites (Hocheng \& Tsao, 2005). For joining with other components these laminates are often subjected to circular holes. The commonly used mechanical joining method are riveting, bolting or pinning joints. These design based holes will interrupt the flux of the force in the direction of the fibers and create high stress concentrations near the notched area. These high notch stress concentrations are often the possible regions for failure in structural parts (Awerbuch \& Madhu, 1985). As a consequence, this weaken the FRP component significant and prevent the optimal exploitation of the high anisotropic lightweight potential of the composites (Seidlitz et al., 2014). Since there is an Increasing usage of FRP laminates in the design of structural parts with high mechanical performance, fatigue behavior of holed FRP laminates requires a better understanding (Kroll et al., 2017; Toubal, Karama, \& Lorrain, 2005).

Drilling is often the final operation during assembly and any associated defects leads to rejection of the composite parts. In the aircraft industry, drilling-associated delamination accounts for $60 \%$ of all part rejections during final assembly of an aircraft (Khashaba, 2004). To overcome this difficulty, this project aims to investigate the quality of the hole produced during drilling and the results are compared with hole produced by $\mathrm{cw}-\mathrm{CO}_{2}$ laser system.

Thermoset composites are often used for high-heat applications because the thermoset matrix doesn't melt like thermoplastics, which makes it as a functional component for automotive thermal management applications. 
Besides thermal management applications, thermoset composites are widely used for due to its excellent dimensional stability, high impact strength, relatively low weight and it makes them as a preferred material in automotive, aerospace, wind energy and marine industries. To maintain the advantages of thermoset composites in automotive components, carbon/epoxy composites are investigated in this study.

\section{Circular Hole in Composite Laminates}

This chapter investigates the quality of the hole produced during drilling and laser methods in FRP laminates. Commercially available unidirectional non crimp carbon fiber and epoxy resin were used to manufacture FRP. $\left[45^{\circ},-45^{\circ}, 0^{\circ}, 90^{\circ}\right] \mathrm{s}$ carbon-epoxy laminates has been manufactured using vacuum assisted resin transfer molding (VARTM) process. VARTM process was preferred because it allows the use of low-cost tooling while still producing high quality composite parts.

The fibre volume fraction of the quasi isotropic composites was maintained at $33 \%$. The investigated material properties are explained in Table 1.

Table 1. Properties of the investigated fiber and epoxy resin

\begin{tabular}{lll}
\hline Properties & Fiber & Matrix \\
\hline & ZOLTEK & Epoxy resin L + Hardener \\
Tensile Strength & $4137 \mathrm{MPa}$ & $74.8 \mathrm{MPa}$ \\
Tensile Modulus & $242 \mathrm{GPa}$ & $3.057 \mathrm{GPa}$ \\
Density & $1.81 \mathrm{~g} / \mathrm{cm}^{3}$ & $1.151 \mathrm{~g} / \mathrm{cm}^{3}$ \\
Poisson's ratio & 0.27 & 0.3 \\
\hline
\end{tabular}

\subsection{Drill Hole Using Milling Machine}

A 3-phase portal milling machine (model: BZT-PFE1010-PX) was used for the introduction of a $6 \mathrm{~mm}$ bore hole in the FRP laminates. $6 \mathrm{~mm}$ spiral high speed steel (HSS) drill tool (model: HOLEX jobber drill tool) with a point angle of $118^{\circ}$ was used to make circular holes as shown in Figure $1.6 \mathrm{~mm}$ circular hole was chosen because mostly the automotive industry used $6 \mathrm{~mm}$ rivets to join multiple parts. Effects of input variables (feed rate, cutting speed) on hole quality were investigated and for each speed, different feed rate was tested (Table 2).

Table 2. List of input variables investigated for milling process

\begin{tabular}{ll}
\hline Input variables & Variation \\
\hline Cutting speed & $3500,5000,10000,15000,20000$ and $24000 \mathrm{~min}^{-1}$ \\
Feed rate & $0.01,0.02,0.1,0.2 \mathrm{~mm} / \mathrm{rev}$ \\
\hline
\end{tabular}

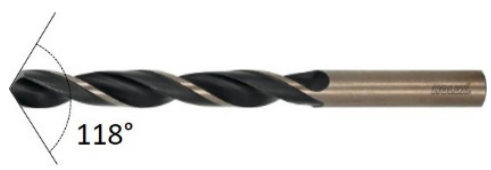

Figure 1. HOLEX 6 mm HSS jobber drill tool used to produce circular holes

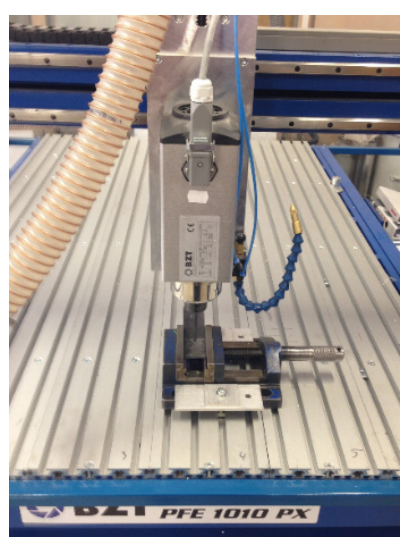

Figure 2. Set-up of the BZT-PFE1010-PX milling machine 
Figure 2 shows the BZT-PFE1010-PX milling machine. With the help of two clamps, sample was tensioned on the work table and a perpendicular load was applied using a drill tool.

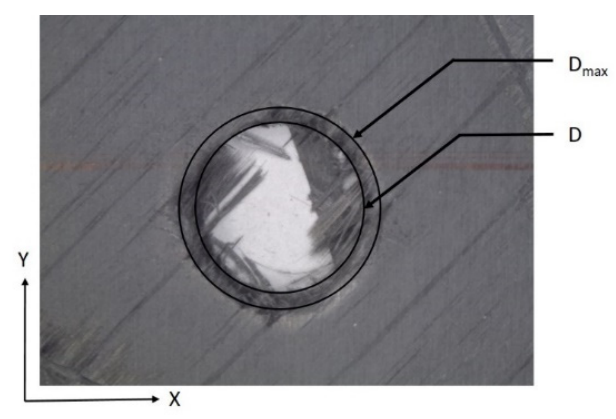

Figure 3. Measurement of the maximum and nominal hole diameter for the $6 \mathrm{~mm}$ diameter hole by a 3-phase portal milling machine

After holes are drilled, it is important to understand the extent of damage caused by the machining process. The hole qualities are evaluated by means of a light microscope (Zeiss Stemi 2000-C) and damage extension surrounding the hole areas were further analysed using the software Imagic ims Client. Factor that enables the evaluation and analysis of delamination extent in laminated composites was called the delamination factor $\left(\mathrm{F}_{\mathrm{d}}\right)$; and it was defined as the ratio of maximum delaminated diameter, $D_{\max }$ and the hole nominal diameter, D (Figure 3) (Durão Luís, Tavares João, Albuquerque Victor de, Marques Jorge, Andrade Oscar, 2014; Shyha Islam, Soo Sein Leung, Aspinwall David, Bradley Sam, 2010).

$$
F_{d}=\frac{D_{\max }}{D}
$$

\subsection{Drill Hole Using $\mathrm{CO}_{2}$ Laser Machine}

Laser technology has been developed in order to reduce the load on the work piece, which is produced during drilling. In recent years, it has been increasingly used in industry because it has advantages such as higher cutting speeds, better flexibility, and higher degree of automation compared to other manufacturing processes (Hocheng \& Tsao, 2005). The $\mathrm{CO}_{2}$ laser produces a beam of infrared light with the principal wavelength bands centering on 9.4 and 10.6 micrometers $(\mu \mathrm{m})$ (Kincade \& Anderson, 2008). Laser marketplace: innovation opens the door for next wave of success. Laser Focus World.,"; Caristan Charles L., 2004). Compared to other materials, the fiber and matrix of CFRP can very well absorb the emitted radiation energy of $\mathrm{CO}_{2}$ laser with a wavelength of $10.6 \mu \mathrm{m}$. Laser technology is also producing less noise and dust. Hence, a $3 \mathrm{D}$ robot assisted $5 \mathrm{~kW}$ continuous wave $\mathrm{CO}_{2}$ laser system ( $\mathrm{cw}-\mathrm{CO}_{2}$ laser) was used for a circular removal of the material from a component of FRP laminates. For the same cutting velocity, the cut quality will be different for glass fibers and carbon fibers respectively. Material damage also occurs owing to thermal stresses which arise during laser cutting due to high thermal gradients near the cutting zone. Due to varying properties of fiber and matrix, processing parameters were varied to identify the suitable processing condition to produce circular holes in FRP.

A typical cw- $\mathrm{CO}_{2}$ laser system consisting of the four basic components: resonator, beam telescope, deflection and phase shifter, as well as cutting head with focusing lens and cutting nozzle (Figure 4). Beam protection tube and bellows surrounding and shielding the laser beam and a plane mirror is used to deflect and guide the laser beam to work station. A semi-reflecting mirror was used to divide the laser beam and a dished mirror used for forming and focusing. The beam phases can be controlled and the direction of the $\mathrm{CO}_{2}$ laser light can be changed by using phase shifter ("Technical Information: Laser processing CO2 laser (2007), TRUMPF werkzeugmaschinen GmbH $+\mathrm{Co}$. $\mathrm{KG})$. 


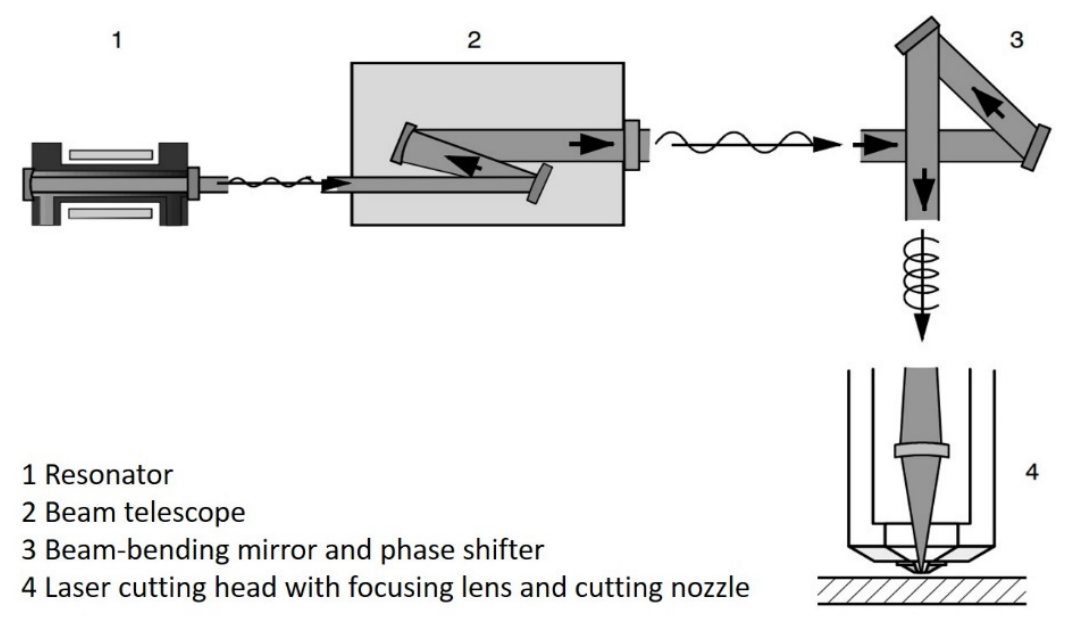

Figure 4. Beam guideway between resonator and workpiece in a cw- $\mathrm{CO}_{2}$ laser system

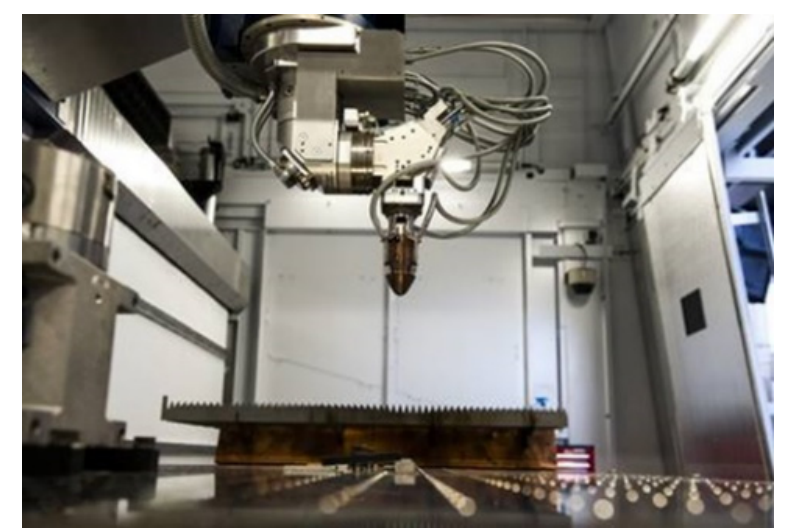

Figure 5. Set-up of 3D robot assisted TRUMPF TruLaser Cell $70405 \mathrm{~kW} \mathrm{cw}-\mathrm{CO}_{2}$ laser system

3D robot assisted TRUMPF TruLaser Cell $70405 \mathrm{~kW} \mathrm{cw}-\mathrm{CO}_{2}$ laser system was used for the introduction of a $6 \mathrm{~mm}$ bore hole in the FRP laminates (Figure 5).

Table 3. List of input variables investigated for laser process

\begin{tabular}{ll}
\hline Input variables & Variation \\
\hline laser power & $250,500,750,1000,1250 \mathrm{~W}$ \\
Feed speed & $1.0,2.5,5.0,7.5,10,12.5 \mathrm{~m} / \mathrm{min}$ \\
\hline
\end{tabular}

Effects of input variables (feed speed, laser power) on hole quality was investigated. For each laser power, different feed speed was tested (Table 3).

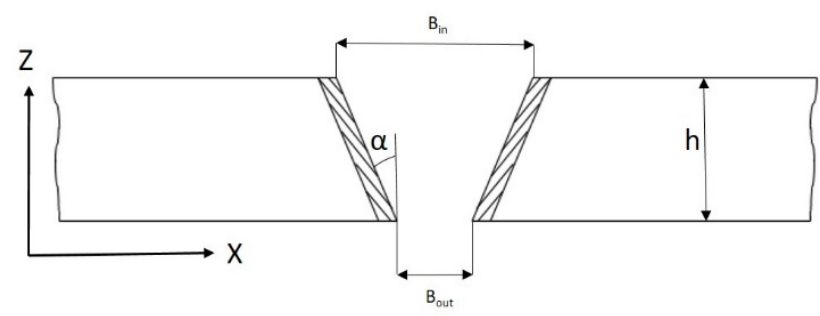

Figure 6. Measurement of the entrance and exit side hole diameter for the $6 \mathrm{~mm}$ diameter hole by a cw- $\mathrm{CO}_{2}$ laser 


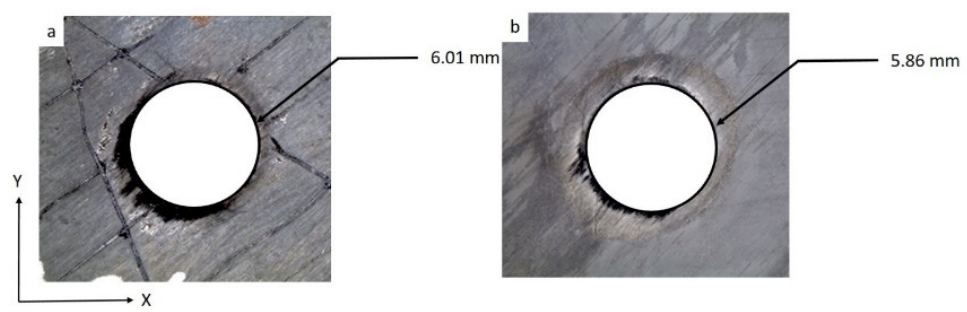

Figure 7. Measurement of the top (a) and bottom (b) hole diameter for the $6 \mathrm{~mm}$ diameter hole by a cw- $\mathrm{CO}_{2}$ laser

The hole qualities were evaluated by means of a light microscope (Zeiss Stemi 2000-C). Cone angle ( $\propto$ ) was determined for each sample (equation 2) and the hole diameter was measured using the software Imagic ims Client (Figure 6 and 7).

$$
\text { Cone angle }(\propto)=\tan ^{-1}\left(\frac{B_{\text {in }}-B_{\text {out }}}{2 h}\right)
$$

$\mathrm{B}_{\text {in }}$ is hole diameter at the laser entrance (top side), $\mathrm{B}_{\text {out }}$ is hole diameter at the laser exit (bottom side), $\alpha$ is Cone angle and $\mathrm{h}$ is thickness of laminate (Leone, Pagano, Lopresto, \& De Iorio, 2009).

\section{Results and Discussion}

\subsection{Milling Machine}

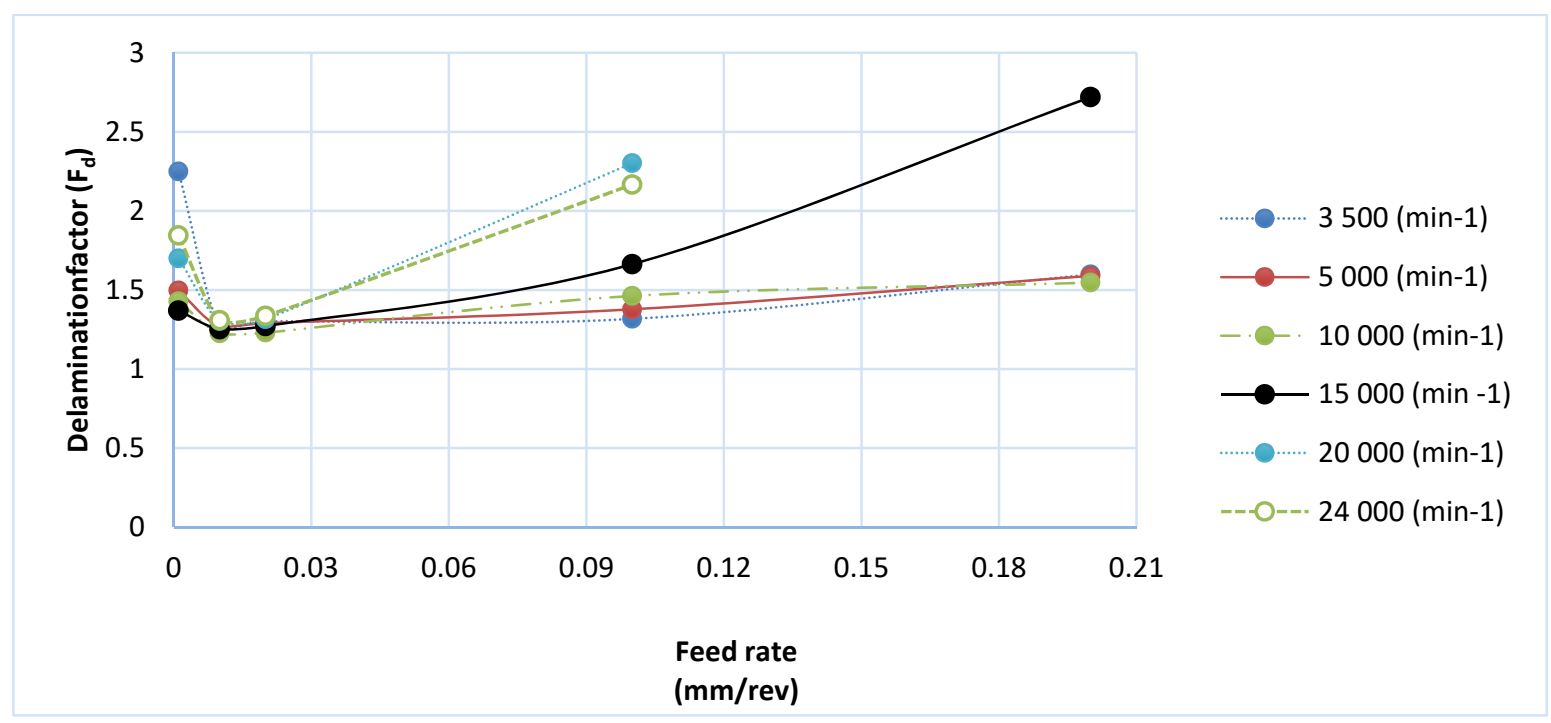

Figure 8. Delamination factors vs feed rate

The effect of feed rate on the fiber delamination factor is shown in Figure 8. Drilling-induced delamination increased with feed rate at any different cutting speed. At $0.001 \mathrm{~mm} / \mathrm{rev}, \mathrm{F}_{\mathrm{d}}$ is higher; the reason is that if the feed rate is too low, the machining time between the spiral drill and the laminate is long, this results in high heat production in the laminates. But if the feed rate is increased then the working time is too low. This results in a large compressive force acting on the work piece, which can lead to delamination (Tsao \& Hocheng, 2007). So in between these two conditions, the optimal condition is at a feed rate of $0.01 \mathrm{~mm} / \mathrm{rev}$.

Figure 9 shows the respective delamination factor on the top and bottom side at varying cutting speeds with a constant feed rate of $0.01 \mathrm{~mm} / \mathrm{rev}$. The figure shows that the lowest damage occurs at a speed of $10000 \mathrm{~min}^{-1}$. 


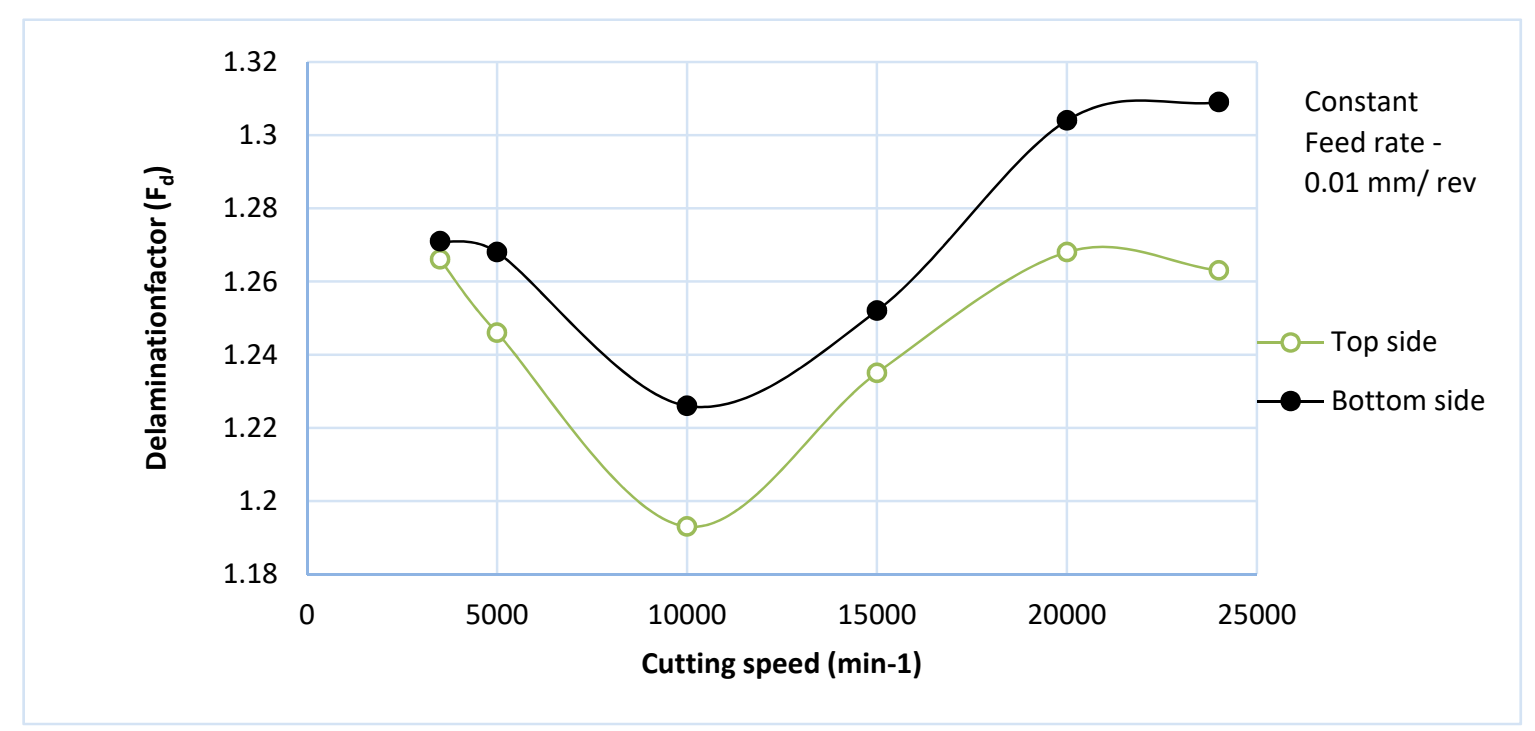

Figure 9. Delamination factors vs Cutting speed at constant feed speed $(0.01 \mathrm{~mm} / \mathrm{rev})$

Table 4. Light microscopic images after milling

$3500 \mathrm{~min}^{-1}$

Table 4 shows the images of the delamination factor of all holes. It shows the influence of speed and feed rate on the quality. It's clear that increasing speed has negative influence on the delamination and increasing feed rate also has negative influence on the delamination. The combination of $10000 \mathrm{~min}^{-1}$ cutting speed and $0.01 \mathrm{~mm} / \mathrm{rev}$ feed rate has the lowest fiber delamination factor. The processing parameters are optimal at this moment. 


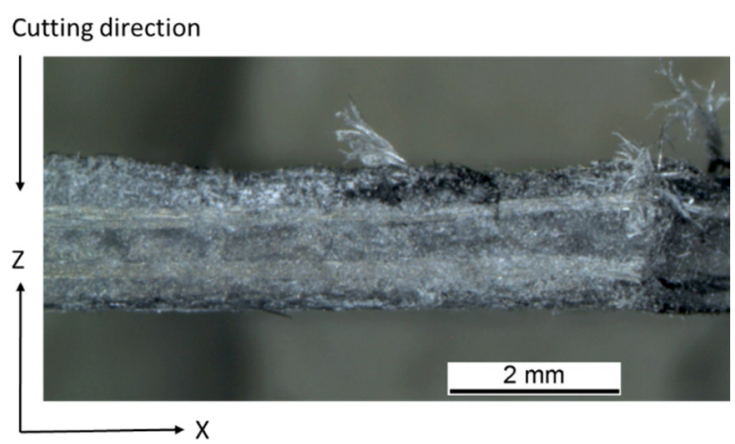

Figure 10. Effect of drilling on the FRP laminates $\left(3500 \mathrm{~min}^{-1}\right.$ and $\left.0.01 \mathrm{~mm} / \mathrm{rev}\right)$

Effect of drilling on the FRP laminates is shown in the microscopic image (Figure 10). Uneven cutting on the top layer of the hole is on the problem faced during the drilling. Delamination and the fibre breakage due to this drilling could have a considerable effect on the performance of the notched FRP laminated by drilling.

\section{$3.2 \mathrm{CO}_{2}$ Laser Machine}

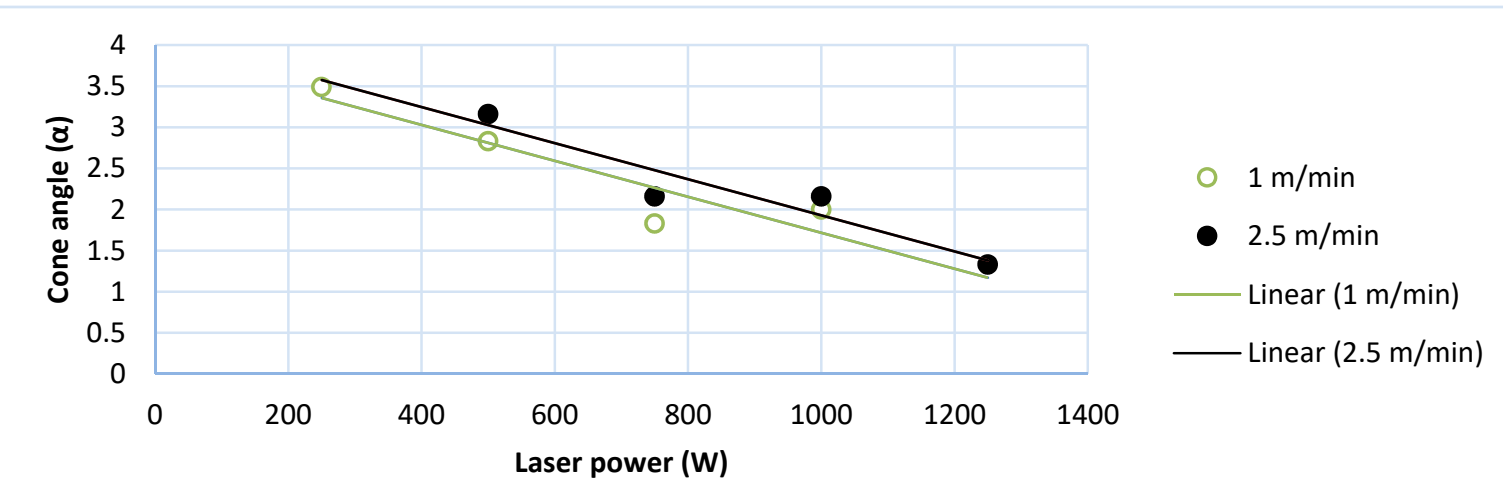

Figure 11. Cone angle vs laser power at constant feed speed "in the attached pdf, the word "Linear $(1 \mathrm{~m} / \mathrm{min})$ " is shown in chinese'

The effect of laser power at constant feed speed on cone angle is shown in the Figure 11. It shows at constant feed speed, there is a decrease in cone angle with increase in laser power. The reason is that the heat is introduced faster into subsequent laminate layers at higher power, this results in removal of excess materials on lower layers (Riveiro et al., 2012; Sivarao et al., 2015).

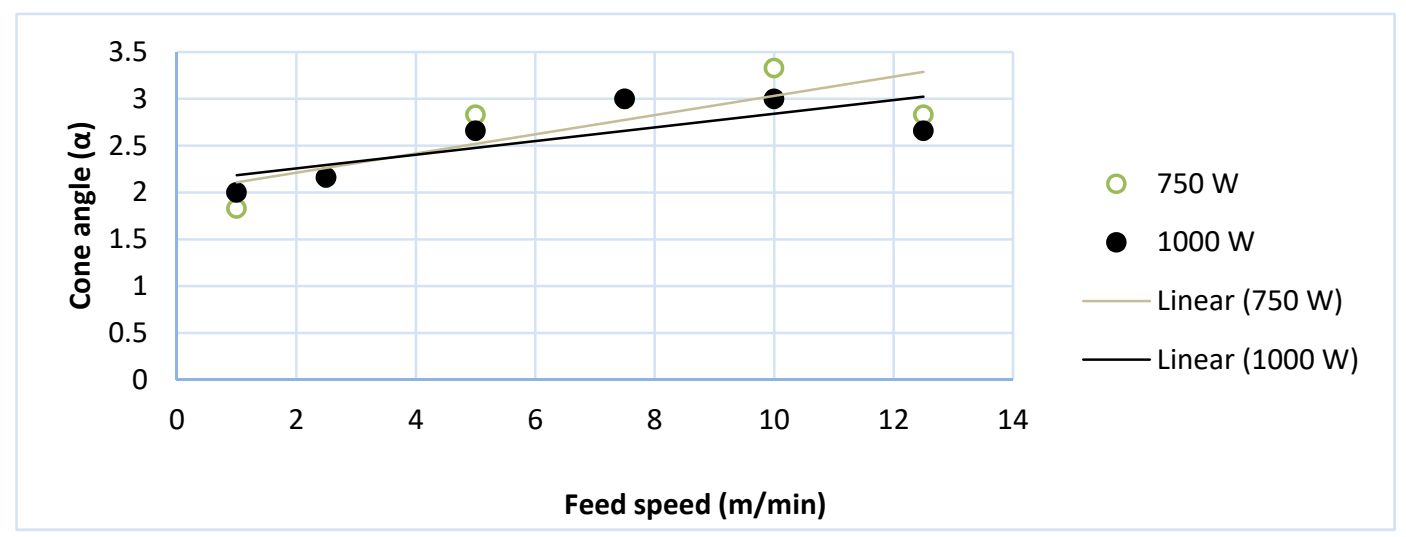

Figure 12. Cone angle vs feed speed at constant laser power "same as figure 11, the word "linear (750W)" is shown in chinease in the attached pdf' 
The effect of feed speed at constant power on cone angle is shown in the Figure 12. It shows at constant laser power, there is an increase in cone angle with increase in feed speed. The reason is that the FRP has less time to evaporate the materials at high cutting speed (De Iorio, Leone, Lopresto, \& Pagano, n.d.).

Table 5. Light microscopic images after laser machining

\begin{tabular}{|c|c|c|c|c|c|}
\hline & $250 \mathrm{~W}$ & $500 \mathrm{~W}$ & $750 \mathrm{~W}$ & $1000 \mathrm{~W}$ & $1250 \mathrm{~W}$ \\
\hline $1 \mathrm{~m} / \mathrm{min}$ & & & & & \\
\hline $2.5 \mathrm{~m} / \mathrm{min}$ & & & & & \\
\hline $5 \mathrm{~m} / \mathrm{min}$ & & & & & \\
\hline $7.5 \mathrm{~m} / \mathrm{min}$ & & & & & - \\
\hline $10 \mathrm{~m} / \mathrm{min}$ & & & & & - \\
\hline $12.5 \mathrm{~m} / \mathrm{min}$ & & & & & - \\
\hline
\end{tabular}

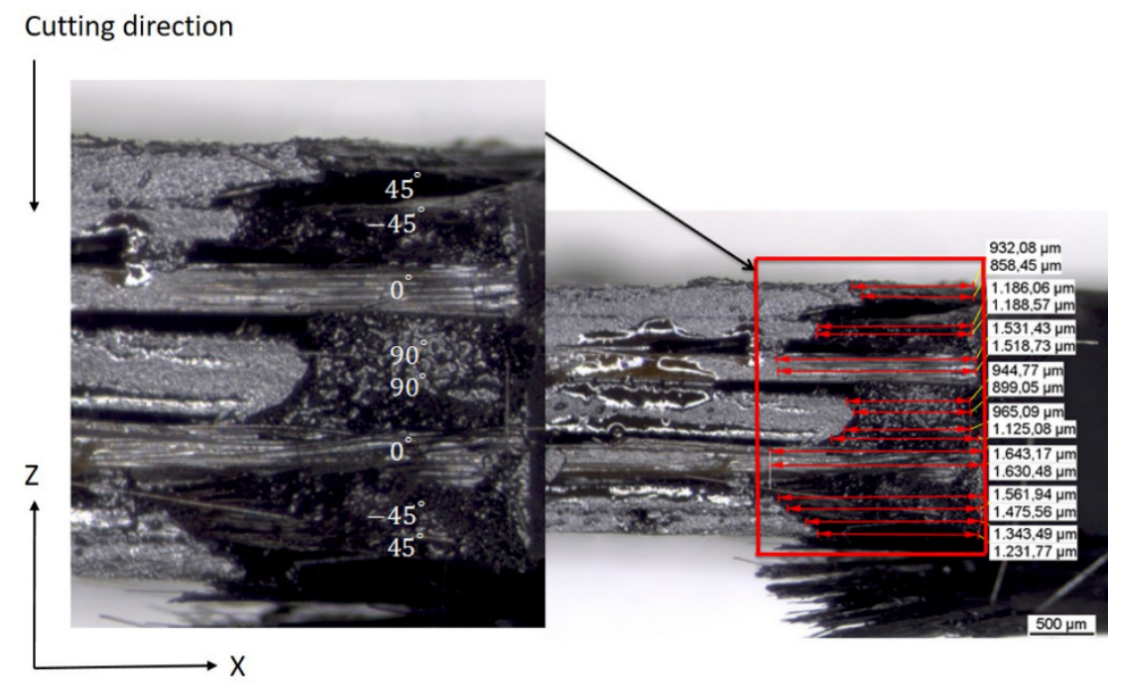

Figure 13. Heat affected zone for each layers of specimen (500 W and $1 \mathrm{~m} / \mathrm{min}$ ) 
Table 5 shows the images of all holes. It shows the influence of feed speed and laser power on the quality. It's clear that increasing laser power has positive influence on cone angle but increasing the feed speed has negative influence on the delamination. The combination of $2.5 \mathrm{~m} / \mathrm{min}$ feed speed and $1250 \mathrm{~W}$ laser power has the lowest cone angle. For mechanical connections, a small cone angle is required. The processing parameters are optimal at this moment.

A low heat affected zone in the FRP laminate is decisive for a good hole quality. Thermal damage induced in composites are due to high thermal conduction of fibres and low vaporisation temperature of the resin. The high thermal diffusivity (which is directly proportional to the thermal conductivity) of carbon fibers accelerates the heat affected zone in the laminates (Di Ilio, Tagliaferri, \& Veniali, 1990; Reza Negarestani). Since the evaporation temperature of the fiber is higher than that of the matrix material, only the region of damage of the matrix in the individual layers is analysed here. Hence the effect of the temperature on the FRP laminate is further investigated. First, each hole is halved using a cutting machine. Both halves are washed with ethanol, dried with a hot air gun and matrix damage length was evaluated by means of a light microscope as shown in Figure 13.

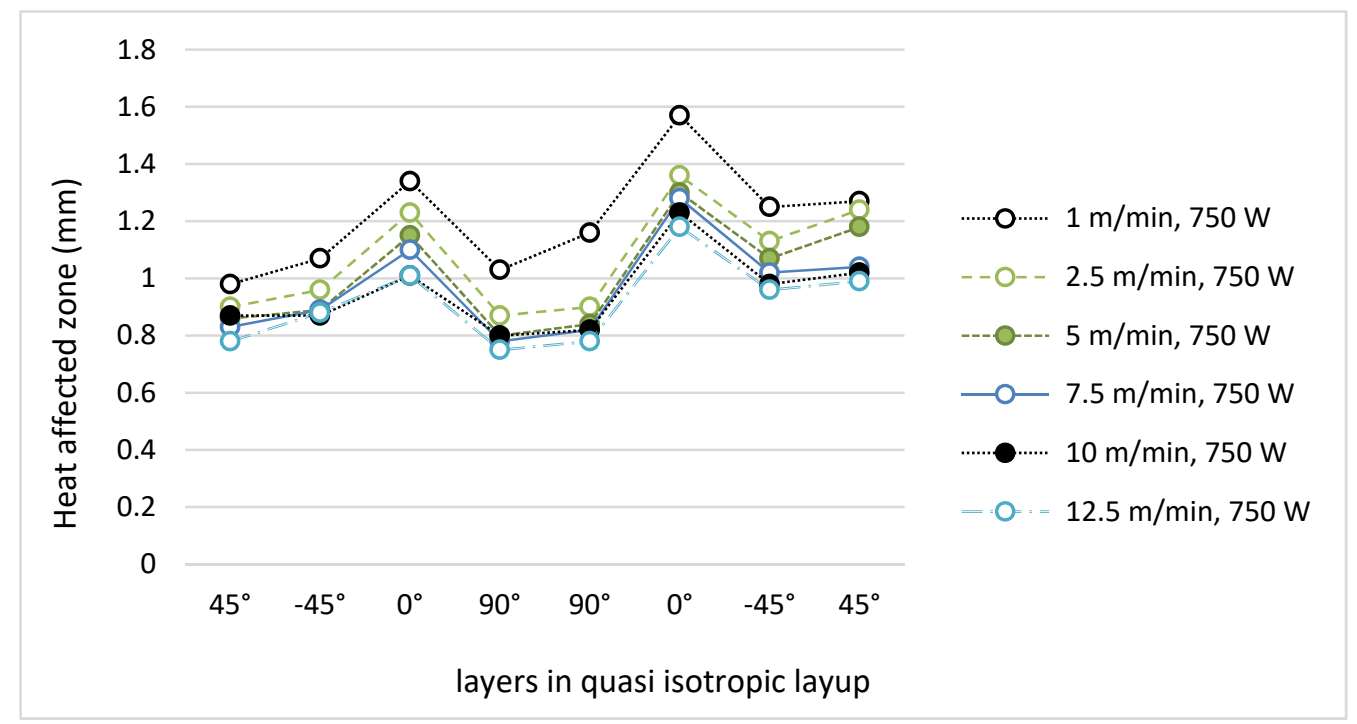

Figure 14. Heat affected zone for each layers of specimen at constant laser power $750 \mathrm{~W}$

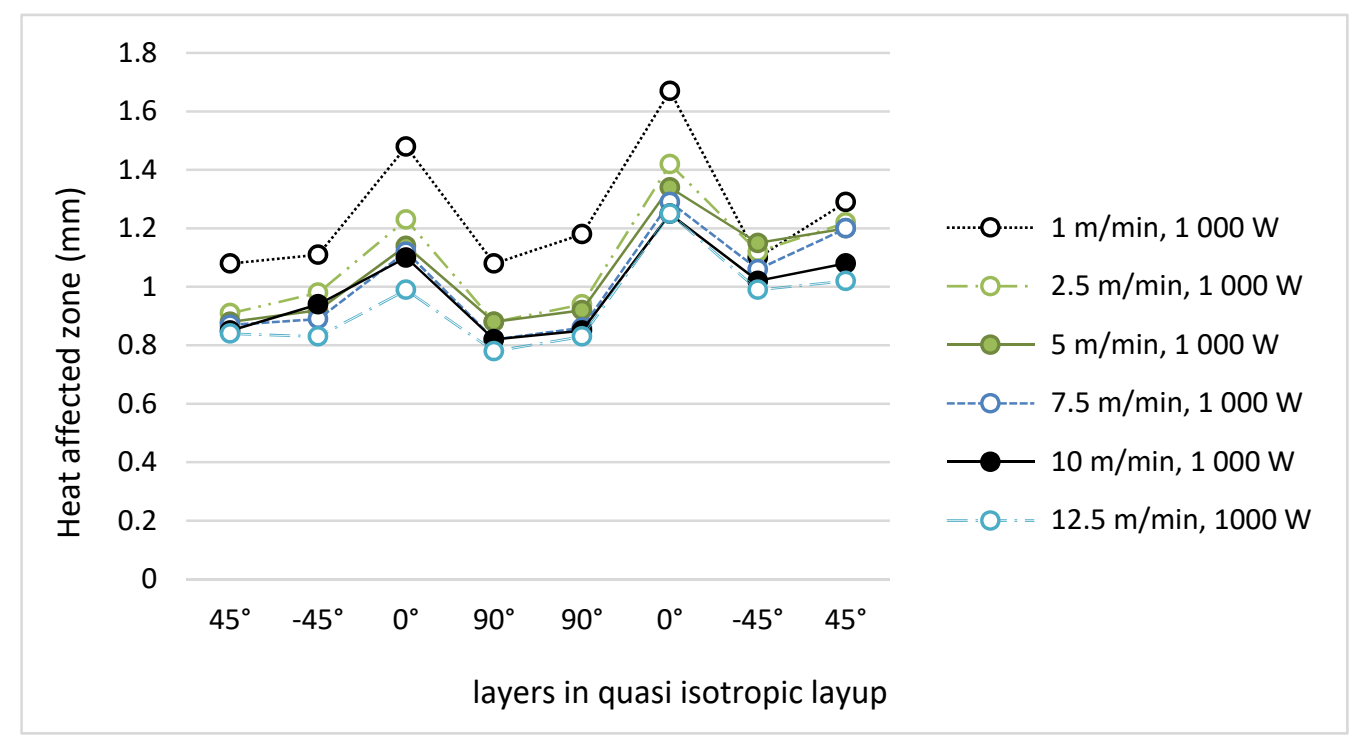

Figure 15. Heat affected zone for each layers of specimen at constant laser power $1000 \mathrm{~W}$ 
Measured matrix damage lengths of the individual samples were plotted over the different carbon fiber layers as shown in Figure 14. It becomes clear that at constant power of $750 \mathrm{~W}$, matrix damage length for each layer decreases with increase in feed speed. The reason is that the matrix material has less time to evaporate at a higher feed rate.

Figure 15 shows that at constant power of $1000 \mathrm{~W}$, with increase in feed speed also has same influence as of 750 W constant power. Matrix evaporation length is always greater in the lower layers than in the upper layers, the reason could be the heat accumulation at the upper layers in the hole have influence on its subsequent lower layers. Furthermore, it is found that the maximum damage to the matrix always occurs in the $6^{\text {th }}$ layer $\left(0^{\circ}\right)$.

\subsection{Tensile Test}
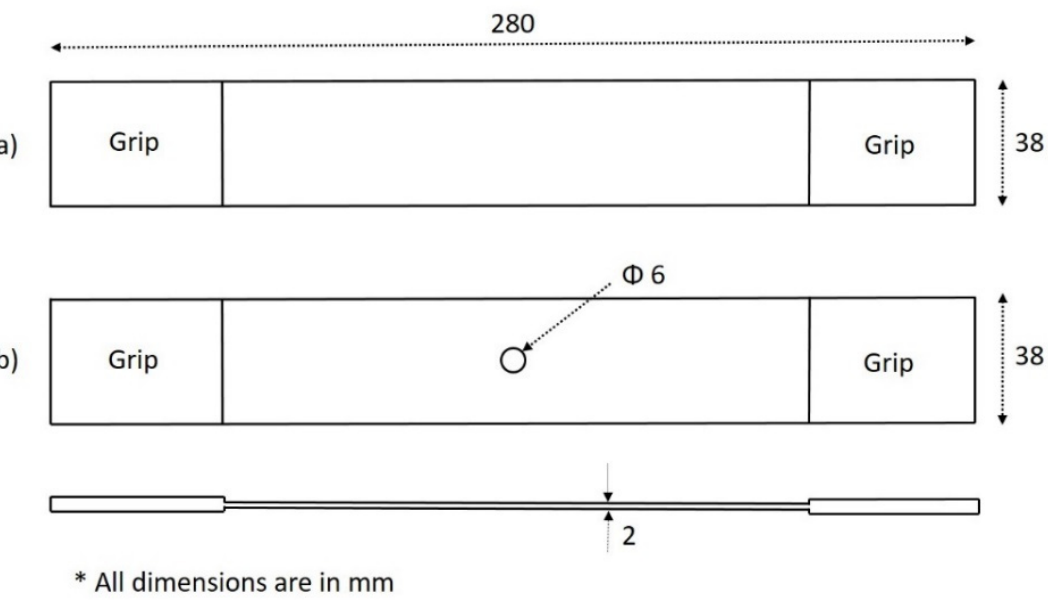

Figure 16. Specimen geometry (dimension in $\mathrm{mm}$ ): (a) unnotched specimen and (b) notched specimen with 6 mm circular hole

For further comparisons, the optimal parameter combinations of both methods were selected for tensile test. The method of experiment is according to the standard ASTM D5766-2002 (Standard Test Method for Open Hole Tensile Strength of Polymer Matrix Composite Laminates,D 5766/D 5766M - 02a) and dimensions are shown in the Figure 16.

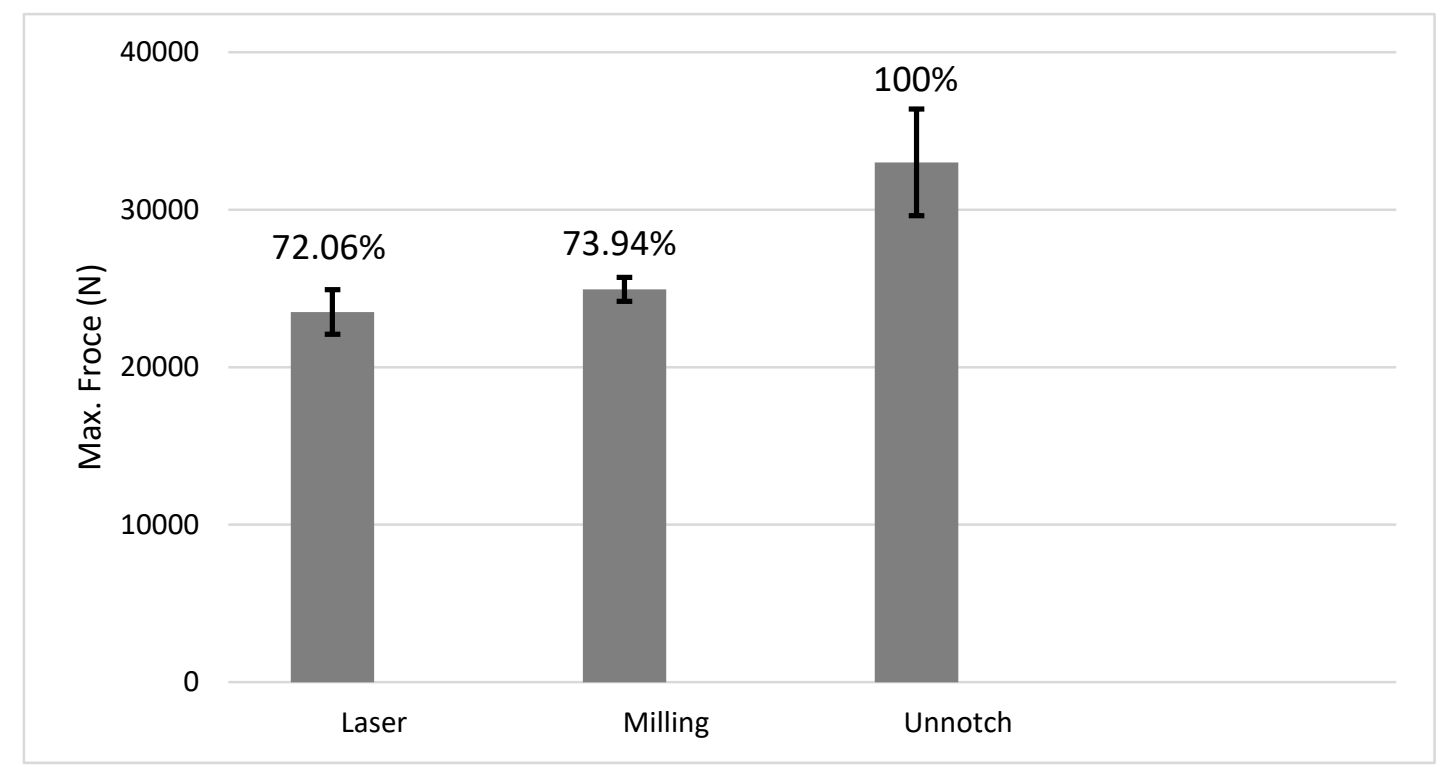

Figure 17. Experimental failure damage of notched and unnotched specimens in tensile test

The tensile test results are shown in the Figure 17. Introduction of the hole by $\mathrm{cw}-\mathrm{CO}_{2}$ lasers caused a reduction of maximum force by $27.94 \%$ compared to unnotched specimen and the drilling results in a reduction of $26.06 \%$. 


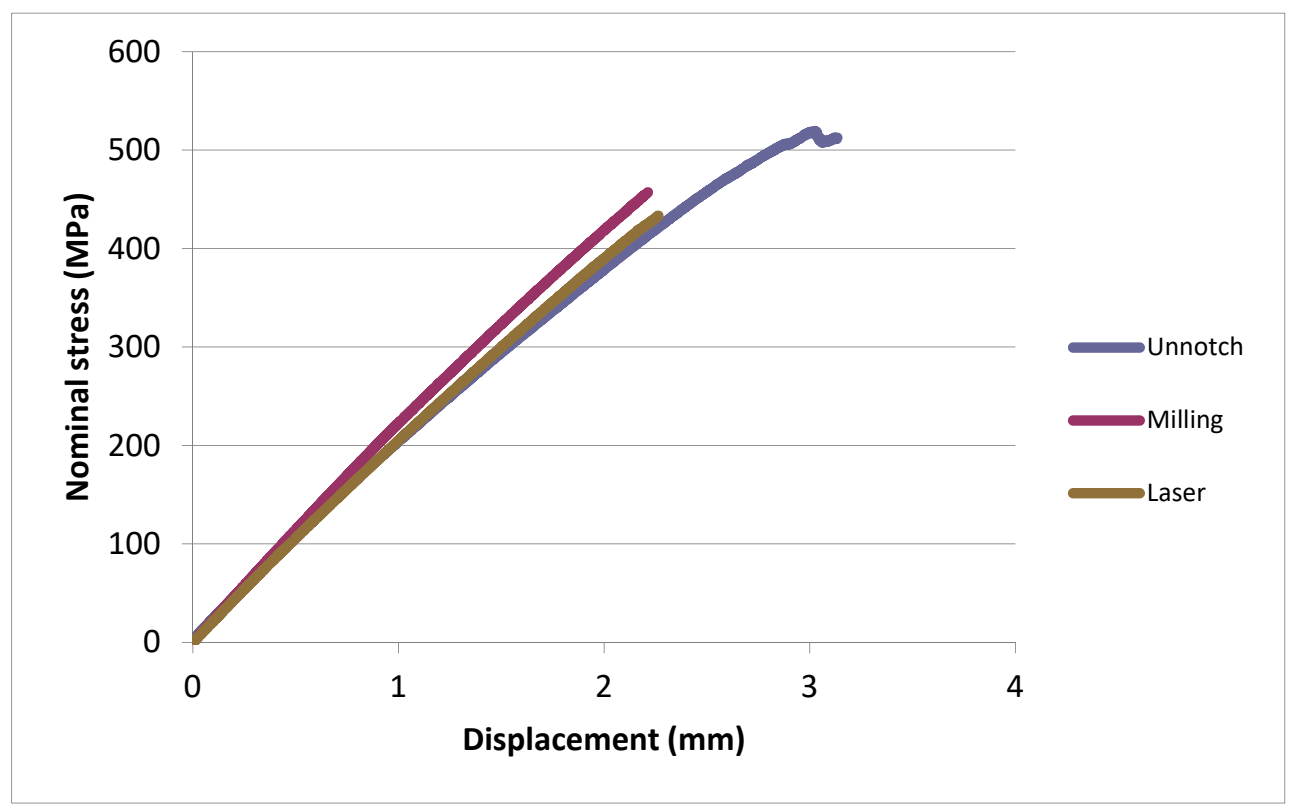

Figure 18. Experimental nominal stress vs displacement curve for notched and unnotched specimens

Size of figure 18 was changed because previously all the paramaeters are not visible

Figure 18 shows the experimentally measured nominal stress-displacement curve for notch specimen by milling, notched specimen by cw-CO2 laser and unnotched specimen. Only a single specimen in each method is chosen for comparison. Curve shows that failure occurs at a displacement of $2.213 \mathrm{~mm}$ for milling, $2.26 \mathrm{~mm}$ for laser and $3.13 \mathrm{~mm}$ for unnotched specimen. It can be observed that both notched specimen had the similar failure behaviour.

\section{Conclusion}

The optimal method for introducing the circular hole was determined by means of maximum loadable tensile force. During drilling, high axial forces at the tip of the drill are selectively induced into the material. The high axial contact forces acting between drills and composites can cause a separation of the layers. These detached layers are the reason for the low load bearing capacity due to drilling. In CO2 laser system, the energy required for evaporation of the fibers is higher than that for the matrix. This phenomenon is most important when a carbon fiber composite is processed, because carbon fibers are good heat conductors, a large portion of the heat energy introduced is derived from the interface during laser cutting. This results in a large volume of resin evaporating during laser cutting. This can lead to high heat affected zone on the composite. This large amount of thermal influence reduces the load bearing capacity compared to unnotched specimen. Introduction of the hole by $\mathrm{cw}-\mathrm{CO}_{2}$ lasers caused a reduction of maximum force by $27.94 \%$ compared to unnotched specimen and the drilling results in a reduction of $26.06 \%$. Since there are only slightly improved characteristic values for milling compared to $\mathrm{cw}-\mathrm{CO}_{2}$ laser process. Laser system can offer high cutting speeds, better flexibility, tool wear and produce less noise and dust compared with milling machine. Laser system offers high degree of automation compared to milling machine because changing drill bit for various diameter hole will increase the processing time in milling and also tool wear will increase delamination in milling. Hence $\mathrm{cw}-\mathrm{CO}_{2}$ laser system can be used for hole machining compared to milling.

\section{Acknowledgments}

The paper was created in the framework of the "LocPro - Local production by smart value chains cluster" in the Graduate Research School established by Brandenburg University of Technology (BTU) Cottbus-Senftenberg. The authors would like to thank BTU for their continuous support throughout the project.

\section{References}

Awerbuch, J., \& Madhu, S. M. (1985). Notched Strength of Composite Laminates: Predictions and Experiments-A Review. Journal of Reinforced Plastics And Composites, 4. https://doi.org/10.1177/073168448500400102

Leone, C., Pagano, N., Lopresto, V., \& De Iorio, I. (2009). Solid state Nd: YAG laser cutting of CFRP sheet: influence of process parameters on kerf geometry and HAZ. 
Caristan, C. L. (2004). Laser cutting guide for manufacturing. Dearborn MI: Society of Manufacturing Engineers.

Di Ilio, A., Tagliaferri, V., \& Veniali, F. (1990). Machining parameters and cut quality in laser cutting of aramid fibre reinforced plastics. Materials and Manufacturing Processes, 5(4), 591-608. https://doi.org/10.1080/ 10426919008953279

Durão, L., Tavares, J., Albuquerque, V. de, Marques, J., \& Andrade, O. (2014). Drilling Damage in Composite Material. Materials, 7(5), 3802-3819. https://doi.org/10.3390/ma7053802

Hocheng, H., \& Tsao, C. C. (2005). The path towards delamination-free drilling of composite materials. Journal of Materials Processing Technology, 167(2-3), 251-264. https://doi.org/10.1016/j.jmatprotec.2005.06.039

Seidlitz, H., Ulke-Winter, L., \& Kroll, L. (2010). Herstellung hochbelasteter Leichtbaustrukturen in Mischbauweise. In: B. Wielage (Ed.), Tagungsband zum 18. Symposium Verbundwerkstoffe und Werkstoffverbunde (Vol. 41, pp. 360 - 365). Chemnitz, Germany: Eigenverl.

De Iorio, I., Leone, C., Lopresto, V., \& Pagano, N. (n.d.). Short pulse Nd:YAG laser cutting of CFRP sheet.

Khashaba, U. A. (2004). Delamination in drilling GFR-thermoset composites. Composite Structures, 63(3-4), 313-327. https://doi.org/10.1016/S0263-8223(03)00180-6

Kincade, K., \& Anderson, S. (2008). Laser marketplace: innovation opens the door for next wave of success. Laser Focus World.

Kroll, L., Kostka, P., Lepper, M., \& Hufenbach, W. (n.d.). Extended proof of fibre-reinforced laminates with holes. Journal of Achievements in Materials and Manufacturing Engineering, 33(1).

Negarestani, R. (n.d.). Laser cutting of carbon fibre-reinforced polymer composite materials. Doctoral thesis at The University of Manchester.

Riveiro, A., Quintero, F., Lusquiños, F., Del Val, J., Comesaña, R., Boutinguiza, M., \& Pou, J. (2012). Experimental study on the $\mathrm{CO} 2$ laser cutting of carbon fiber reinforced plastic composite. Composites Part A: Applied Science and Manufacturing, 43(8), 1400-1409. https://doi.org/10.1016/j.compositesa.2012.02.012

Seidlitz, H., Gerstenberger, C., Osiecki, T., Simon, S., \& Kroll, L. (2014). High-performance lightweight structures with Fiber Reinforced Thermoplastics and Structured Metal Thin Sheets. Journal of Materials Science Research, 4(1). https://doi.org/10.5539/jmsr.v4n1p28

Shyha, I., Soo, S. L., Aspinwall, D., \& Bradley, S. (2010). Effect of laminate configuration and feed rate on cutting performance when drilling holes in carbon fibre reinforced plastic composites. Journal of Materials Processing Technology, 210(8), 1023-1034. https://doi.org/10.1016/j.jmatprotec.2010.02.011

Sivarao, S., Sivakumar, D. M., Taufik, Yuhazri, Y., Tan, C. F., \& Haeryip , S. (2015). An Exploratory Study Critical Laser Processing of Composite Materials. International Journal of Engineering Research \& Technology.

Standard Test Method for Open Hole Tensile Strength of Polymer Matrix Composite Laminates, D 5766/D 5766M $-02 \mathrm{a}$.

Sudarsono, O. K. (2017). Fatigue Behavior of Open-Holed CFRP Laminates with Initially Cut Fibers. Open Journal of Composite Materials, 07(01), 49-62. https://doi.org/10.4236/ojcm.2017.71003

Technical Information: Laser processing CO2 laser. (2007). TRUMPF werkzeugmaschinen $\mathrm{GmbH}+\mathrm{Co}$. KG.

Toubal, L., Karama, M., \& Lorrain, B. (2005). Stress concentration in a circular hole in composite plate. Composite Structures, 68(1), 31-36. https://doi.org/10.1016/j.compstruct.2004.02.016

Tsao, C. C, \& Hocheng, H. (2007). Effect of tool wear on delamination in drilling composite materials. International Journal of Mechanical Sciences, 49(8), 983-988. https://doi.org/10.1016/j.ijmecsci.2007. 01.001

\section{Copyrights}

Copyright for this article is retained by the author(s), with first publication rights granted to the journal.

This is an open-access article distributed under the terms and conditions of the Creative Commons Attribution license (http://creativecommons.org/licenses/by/4.0/). 